bindungen zeigt es ein demselben durchaus analoges Verhalten, steht ihm auch an Glanz, Ductilität, Politurfähigkeit und Beständigkeit an der Luft nicht nach, an Härte aber ungefähr gleich. Die Farbe ist weniger weiss und zeigt einen unverkennbaren Stich in das Gelbliche, jedoch viel weniger als Wismuth; ${ }^{*}$ ) in trockner Luft ist es ebenfalls nicht beständig, an feuchter läuft es anfangs nicht wie Lanthan stahlblau, sondern gelblich an. Ungeschmolzenes Didym ist nur wenig härter als ungeschmolzenes Cerium; erst bei sehr heftiger Ritzung des letztern durch Didym erhält man von selbst sich entzündende Ceriumspäne. Die feinen Späne, welche bei dem Schaben und Ritzen des Metalls abspringen, entzünden sich nicht von selbst, sondern verbrennen erst in die Flamme gebracht, dann aber mit eminenter Lichterscheinung. Von polirten Flächen des Didyms reflectirtes Licht zeigt die Absorptionsstreifen, welche das Oxydul unter denselben $\mathrm{Um}$ ständen erkennen lässt, nicht. Sein spec. Gewicht ist 6,544.

Diese drei Metalle sind electropositiver als Zink, aber electronegativer als Magnesium.

\title{
Mittheilungen aus der Praxis.
}

Von A. Wentz in Glan-Münchweiler.

I. Ueber Pfefferuntersuchungen.

In letzterer Zeit vielfach mit Untersuchungen von Pfefferproben auf fremdartige Beimischungen beschäftigt, mag folgende kleine Mittheilung beachtungswerth sein.

Am zweckmässigsten verfährt man, ehe man zur mikroskopischen Untersuchung schreitet, dass man einen Theil der Pfefferprobe durch Sieben von dem feinen Staube trennt, und den gröberen zurückgebliebenen Theil mit einer guten Loupe untersucht, was bei einiger Uebung in der Regel zur Erkenntniss des Fälschungsmittels führt, da der Pfeffer meistens in

*) Wenn dieser Vergleich mit dem Wismuth richtig ist, so müsste der Stich nicht als gelblicher, sondern als röthlicher bezeichnet werden.

$W$.

Arah. d. Pharm. IX. Bda. 5. Heft. 
einer grob gemahlenen Form in den Handel gebracht wird. Als Zusatzmittel fand ich bei we issem Pfeffer Reis, Wälschkorn und Bohnentheile, letztere auch an den Schalenresten leicht erkennbar, bei schwarzem Pfeffer, Bohnen, Reis, Wälschkorn, Erbsen, Holz und schalenartige Theile derselben, auf letztere Art des Betruges wurde ich orst bei längerem Betrachten mit der Loupe aufmerksam. Alle diese verschiedenartigen Beimischungen können, die meisten leicht, einige nur schwer mit einer Pincette unter Beihilfe einer Loupe ausgelesen und dem Gutachten als fernerer Beleg beigefügt werden.

Für die mikroskopische Untersuchung wurde ein Theil der ganzen Probe sehr fein gepulvert; im Minimum auf ein Objectglas gebracht, nach Aufsetzen des Deckelgläschen, Zufügen eines Tropfen destillirten Wassers, leichtes Aufdrücken zur Entfernung der Luftbläschen, bei einer 480 fachen Vergrösserung untersucht. Bei dieser Vergrösserung erscheinen die runden Pfefferstärkekörperchen in der Grösse eines Stecknadelkopfes und unterscheiden sich sehr scharf von denen der Getreidearten, Leguminosen durch ihre Grösse und vielseitige Gestalt. - Doch ist absolut erforderlich, sich vorher mit der Form der verschiedenen Stärkmehlkörperchen durch eigene dazu präparirte Proben bekannt zu machen, wozu die trefflichen Abbildungen von Dr. Hager in seinem Werkchen ,Das Mikroskop“, sowie die sehr guten Objecte von C. Rodig aus Hamburg als Unterstïtzung dienen können. Auch die genauen Aschenbestimmungen, wenn man sich dieser Mühe unterziehen will, gewähren gute Anhaltspunkte zur Beurtheilung der Reinheit des Pfeffers, die nach meinen Bestimmungen auf die bei $100^{\circ}$ getrocknete reine Waare zwischen 4,1-4,94 wechseln.

Sehr anzurathen ist ferner, sich immer zwei versiegelte nicht zu kleine Proben eines.jeden Pfeffers von der Polizei geben zu lassen, von denen man die eine Probe zur Untersuchung verwendet, die andere deponirt, damit man bei allfallsiger Berufung auf die Richtigkeit der Untersuchungsresultate sich stützen kann. 
II. Spiritus et Tinctura Formicarum.

Jeden Sommer mit der Destillation grösserer Portionen Ameisenspiritus beschäftigt, fand ich, dass es vortheilhaft ist, ehe man zur Destillation schreitet, den Ansatz in einer Schraubenpresse stark auszupressen und bei raschem Feuer zu. destilliren, dadurch gewinnt man ein an Ameisensäure reicheres Destillat.

30,0 Spiritus erforderten nach Zusatz von Lackmus 13,1 halb normal Ammoniak, einem Gehalte von $1 \%$ Ameisensëure in 100 entsprechend.

Bei 30,0 Tinctura Formicarum, mit Hilfe ron empfindlichen Lackmuspapier bestimmt, waren 29,9 halb normal Ammoniak zur Neutralisation erforderlich, einem Gehalte von 2,28\% Ameisensäure in 100 Theilen entsprechend, mithin ist die Tinctur das wirksamste Präparat. -

\section{B. Monatsbericht.}

\section{Nene Spectrallinien des Calcium.}

In einem Brief von Lockyer an Dumas schreibt derselbe: Ich bin ziemlich vorgerückt in der Anfertigung einer Karte des Sonnenspectrums, welche den vierfachen Massstab derjenigen von Angström haben soll, und habe ich dabei mit jener Region angefangen, von welcher kürzlich Cornu eine so schöne Karte veröffentlicht hat.

Mein System besteht darin, die Elemente des Sonnenkörpers dadurch zu bestimmen, dass ich auf ein-und dieselbe Platte das Sonnenspectrum und das Spectrum verschiedener chemischer Grundstoffe photographire. Ich habe dieses schon mit einer grossen Zahl von Elementen und bei verschiedenen Temperaturen ausgeführt. Auf einen eigenthümlichen, dabei hervorgetretenen Umstand möchte ich hiermit Ihre Aufmerksamkeit lenken. Wenn man z. B. Chlorcalcium nur in geringem Grade dissocïrt, so erbält man die blaue Calciumlinie und ausserdem ein beinahe vollständiges Spectrum unzersetzten Calciums. In dem Maasse, als die Dissociation des 